\title{
Raising Awareness of Potential Biases and Microaggressions: Applications to Mediation
}

\author{
Alan E. Gross
}

\begin{abstract}
"Neutrality" or "impartiality" are well accepted and practiced values that are important cornerstones of mediation; nonetheless mediators usually bring biases and preferences with them into the room, as do the parties. Mediators are responsible for becoming aware of these biases, especially when they are unconscious, so that they can conduct themselves in an impartial manner. Mediators sometimes can encourage parties to bring their biases into the open where they can be dealt with more effectively. Especially difficult kinds of insulting behavior are "microaggressions" defined as minor slights that are usually well-intended by parties and mediators. This article is intended to raise awareness of biases and microaggressions, and to suggest means for preventing them and ways of responding to situations in which they commonly occur.
\end{abstract}

\section{Keywords}

Microaggressions, mediation, microinsult, neutrality, impariality

Microaggressions are small verbalizations or other behaviors which, intentionally or not, are perceived as insulting, demeaning or biased (e.g., racist, sexist, homophobic) by the victim or target person. For example: "you are a credit to your (race, gender, etc.)" may communicate that the target group is not as intelligent as (whites, men, etc.). Because majority culture people, including mediators, are often unaware that they are sending negative messages, sensitizing them to the effects of such behavior on targets can considerably reduce such unwanted behavior.

The term "microaggression" was introduced by Charles Pierce in the 1970s (Pierce et. al., 1978). Pierce's concept was largely based on and confined to subtle and not-so- subtle racism in broadcast television in the 1970s and earlier. However, in the early $21^{\text {st }}$ century, Prof. Derald Sue and his colleagues have identified microaggressions in many settings, and have broadened the concept to include sexism, homophobia and much more. Sue's book "Microaggressions in Everyday Life" (Sue, 2010) is the definitive and comprehensive work in the field. Sue and his colleagues describe $\mathrm{many}$ varieties of microaggressions as presented in a taxonomy in their seminal American Psychologist article (Sue et. al. 2007). Among the examples quoted in that article: "You speak good English" (assumption that an Asian 
or Latino American is foreign born); "You are a credit to your race" (it is unusual from someone of your race to be intelligent); "When I look at you I don't see color" (you should assimilate to the dominant culture; denying a person's racial/ethnic experiences); “I'm not racist. I have several black friends" (I am immune to racism because I have friends of color); "Everyone can succeed if they work hard" (People of color are lazy/incompetent and need to work harder).

Subcategories of Microaggressions such as Microinsults and Microinvalidations are usually related to race, ethnicity or gender but they can also occur as an (unintentional) expression of various "isms" including Ableism, Adultism, Ageism, Classism, Ethnocentrism, Heterosexism, Homophobia, Racism, Religious bigotry, Sexism, and Sizism. Many other concepts are related to Microaggression and biased treatment of others including bias, bigotry, culture, prejudice, scape-goating, and positive and negative stereotyping.

It should be noted that although Sue and many others introduced the microaggression concept in order to increase awareness among both potential perpetrators and victims so that harm to victims could be reduced or eliminated, a recent backlash has emerged from those who equate attempts to reduce microaggressions with "political correctness," or suppression of free speech as championed by the first amendment to the U.S. Constitution. When some American universities specified what kind of microaggressions were not acceptable in the classroom and elsewhere, those directives evoked especially intense negative reactions. See for example Prof. Volokh who accuses the University of California administration of suppressing viewpoints and even attacking academic freedom: https://www.washingtonpost.com/news/volokh-conspiracy/wp/2015/06/16/uc-teaching-facultymembers-not-to-criticize-race-based- affirmative-action-call-america-melting-pot-and-more

However, in the practice of mediation, and elsewhere in the social world, I fail to see a conflict between freedom of expression and the desire to prevent harm to victims of microaggressions. Considerate citizens already observe, often voluntarily, limits on what they express from not shouting "fire" when panic might result, to subtler restrictions such as naming ethnic, racial and other groups by the labels that they prefer. Mediators would likely come down on the side of protecting parties from bias ranging from intentional insults to subtle or unintended microaggressions. As Sue and others suggest, the first step in reducing the negative impact of such comments is to make them visible so that they can be unpacked, clarified, and discussedopenly.

Defining and recognizing microaggressions is difficult but it is only a first step (Sue, 2010: 40). The mediator must then decide whether to intervene and how. Two basic kinds of microaggressions can occur at the mediation table: 1) one of the parties may unintentionally microaggress against another party 2) mediators may themselves become a perpetrator or, very rarely, a target of a microaggression. In the second case the perpetrating mediator who becomes aware that he/she has targeted one or several parties, especially if they react negatively, may effectively apologize for the unintended insult/slight. The first case is more problematic because a mediator intervention to protect the party who is the target of a microaggression, or to criticize or "educate" the perpetrator could compromise impartiality or provoke defensiveness. In such cases, an intervention in caucus might be preferable. In general, targets of 
microaggressions are often conflicted about whether and how to respond. Pushing back in anger could exacerbate or lead to accusations of oversensitivity, but not responding may also be psychologically difficult. By recognizing and commenting on an microaggression, the mediator can possibly take the burden of responding from the target/victim. Parties who intentionally or even inadvertently express overt racism might expect a negative reaction; however, microaggressors are often surprised by negative reactions because their intention is often to compliment or relate to the target.

My focus here is to borrow ideas from Sue and others who write about microaggression and to apply them to what can happens at the mediation table. Although microaggressions do not frequently occur during mediation, mediation sessions are not immune from such subtle biases. A colleague at a New York City community mediation center recently described these two incidents, one non-verbal and one a verbal "compliment": 1) In a waiting room she observed a mediator warmly greet a white male party with a friendly hand shake, but only nodded a greeting at a black female party. 2) In an emotional session involving an African American mother and her teen son, a white middle-aged female mediator addressed the son with 'You're a tall good looking black youth. Why not try some athletics or a part-time job?" These two well- intended recommendations had almost nothing to do with the content of the session (fighting at school). In the latter case, the co-mediator was aware of the microaggression, and called a recess to counsel her partner. One means of sensitizing mediators to such problems is to present them with hypothetical scenarios during training.

Here is one such handout that I have used at trainings.

1) You and your partner are mediating a dispute where one of the parties is black. You are white and your partner is black. At one point during the mediation, the black party looks at you and says that you cannot understand what he/she is dealing with, and then turns to your black partner and suggests that your partner must be able to understand his/her problem. How would you handle this situation?

2) You are co-mediating with partner of opposite gender. Parties are two men from Latin America who direct all their comments and eye contact to the male co-mediator. How would you handle this situation?

3) You are mediating a dispute between neighbors at a community mediation center. During a caucus, one party says that they don't get along because he is Puerto Rican and the other party is Dominican and hates Puerto Ricans. It appears to you that the complaints about noise and other problems in the relationship are very closely related to the Dominican party's dislike of the Puerto Rican party, and that the hatred arises out of their different background. How would you handle this situation?

4) You are mediating a dispute between neighbors at a community center. Based on comments made by Party A, it becomes clear that one of the main causes of the many problems that the two parties have is that Party A doesn't like Party B because Party B is gay. Party A cannot comprehend how or why anyone would lead such a "disgusting life". How would you bandle this situation?

5) You and your partner are mediating a case involving a Muslim couple on one side. The wife never answers or makes eye contact. You secede to ask to speak to the wife alone. Husband visibly upset. 


\section{How would you handle this situation?}

6) You are one of two middle age white women mediating a PINS case involving a black $7^{\text {th }}$ grader and his parents. While the two parents appear comfortable speaking with you, the boy refuses to speak. You employ a variety of techniques in an attempt to engage him, yet nothing works. You sense that this young boy may not feel comfortable speaking openly with two middle aged white women, and this discomfort may be a significant factor in his silence. How would you handle this situation?

7) You and your co-mediator, who you are working with for the first time, are mediating at a community center. Your co-mediator is a white middle aged man and you are Asian.

At one point when the two parties are out of the room, he comments how much easier this mediation would be if the parties, one of whom is black and the other Latino, had been raised as Asians raise their kids. He further explains that Asian kids are obedient, hard-working and rarely cause trouble. You feel that he is doing a reasonably good job mediating, but are a bit put off by his comments. How would you handle this situation?

The following general recommendations may reduce or eliminate some of the problems noted here and in the training handout:

1) It is an important mediator responsibility and skill to acknowledge their own biases, but to keep them in check by displaying neutral behavior during a session.

2) If a bias affecting mediation becomes obvious, be transparent, own it, and recuse yourself if necessary.

3) There are occasions where parties need you to help focus their conflict on particular aspects of a dispute that may deal with bias or prejudice - so if there is an elephant or even a pesky mouse in the room, acknowledge it and ask the parties if it is an issue. Obvious isms should not be ignored or disregarded if they are a possible factor in mediation.

4) Sometimes the parties will want or need you to address an underlying aspect of the conflict but they are inhibited from stating it out loud. Be brave and say it out loud - allowing room to be wrong. Once an issue is said out loud, it may be useful to discuss it before moving on.

5) We tend to classify people that we do not know in categories such as gender, race, and age and assume that various characteristics cluster together. Only some of these assumptions and biases are true. Since assumptions are not always accurate, a better way to acquire knowledge about a person is to check out assumptions by asking questions, preferably open-ended.

In conclusion, microaggressions can easily find their way into the mediation room; however, mediator awareness can often prevent such slights. 


\section{References}

Pierce, C. Carew, J., Pierce-Gonzalez, D., \& Willis, D. (1978). An experiment in racism: TV commercials. In C. Pierce (Ed.), Television and Education. 62-68. Beverly Hills, California: Sage.

Sue, D.W., Capodilupo, C.M, Torina, G. C.Bucceri, J.M, Holder, A.M.B, Nadal, K.L.Esquilin, M. (2007) Racial microaggressions in everyday life: implications for clinical practice. American Psychologist, 62:4, 271286.

Sue, D.W. (2010) Microaggressions in Everyday Life: Race, Gender, and Sexual Orientation. Hoboken, New Jersey: John Wiley and Sons.

Alan E. Gross, Ph.D. has mediated, arbitrated, facilitated, and trained for over 25 years at many venues in the Northeast US and especially New York City where he has served as the Special Projects Coordinator and Board Director for the New York Peace Institute (formerly Safe Horizon) Mediation Program, and has previously acted as Senior Director, Training Coordinator and 9/11 Family Mediation Coordinator for Safe Horizon. That work with 9/11 victims was recognized with a US Department of Justice Volunteer for Victims Award.

He has also been appointed as ombudsman for the American Psychological Association and the New York Mayor's Action Center, as an arbitrator for AAA, FINRA, and attorney-client fee disputes and as mediator for the US Postal Service and the US Army.

Gross holds MBA and Ph.D. degrees from Stanford University and was formerly Psychology Professor and Department Chair at the University of Maryland. He is a Fellow of the Association for Psychological Science, and the author of a textbook and more than 50 chapters, articles and papers related to conflict resolution and social psychology. He is the recipient of the 2011 ADR Achievement Award from the Association for Conflict Resolution, Greater NYC Chapter, and teaches graduate courses in mediation skills at the NYU Center for Global Studies.

As a Founding Member of Mediators Beyond Borders, he has developed and delivered trainings and other assistance for Liberian refugees, Ghanaian attorneys and land settlement officers, UN special staff in Sierra Leone and a diverse country-wide Peace Network in Iraq. 